\title{
Ectopic Intra-Nasal Tooth: A Case Report
}

\section{Anajar S, Tatari MM*, Wydadi O, Rouadi S, Abada R, Roubal M and Mahtar M \\ Department of ENT, 20 August 1953 Hospital in Casablanca, Morocco}

*Corresponding author: Tatari MM, Department of ENT, 20 August 1953 Hospital in Casablanca, Morocco, E-mail: tatari_moutaa@hotmail.com

Citation: Anajar S, Tatari MM, Wydadi O, Rouadi S, Abada R, et al. (2017) Ectopic Intra-Nasal Tooth: A Case Report. J Case Rep Stud 5(4): 402. doi: 10.15744/2348-9820.5.402

Received Date: May 23, 2017 Accepted Date: August 28, 2017 Published Date: August 30, 2017

\begin{abstract}
An ectopic tooth in a nasal cavity is a rare phenomenon. In most cases, no etiological explanation of teeth in that location has been suggested or found. We report the case of a 26-year-old man, who discovered, 5 years ago, an induration inside his right nasal pit, which caused an unilateral nasal obstruction, without rhinorrhea, with epistaxis, revealing an ectopic in intra-nasal tooth.

Keywords: Tooth; Intranasal; Ectopic
\end{abstract}

\section{Introduction}

Ectopic intra-nasal teeth locations are very rare phenomenon, and can occur in several other places in the body. The incidence of these intranasal ectopic teeth varies between 0.1 and $1 \%$ in the general population [1]. They can be found in the palate, the maxillary sinus or the floor of the nasal cavity. Even cases in the lower turbinate have been reported. It is important to identify these ectopic teeth, because of the morbidity they can cause.

\section{Case report}

We report the case of a 26-year-old man with no notion of facial trauma or any other significant pathological history, who witnessed, 5 years ago, the development of an induration inside his right nasal cavity, causing painful nasal unilateral obstruction, epistaxis episodes without rhinorrhea. The clinical examination found a hard mass in the floor of the right nasal fossa, covered by mucous membrane and purulent secretions, with a repression of the nasal septum which was deflected towards the controlateral side (Figure 1).

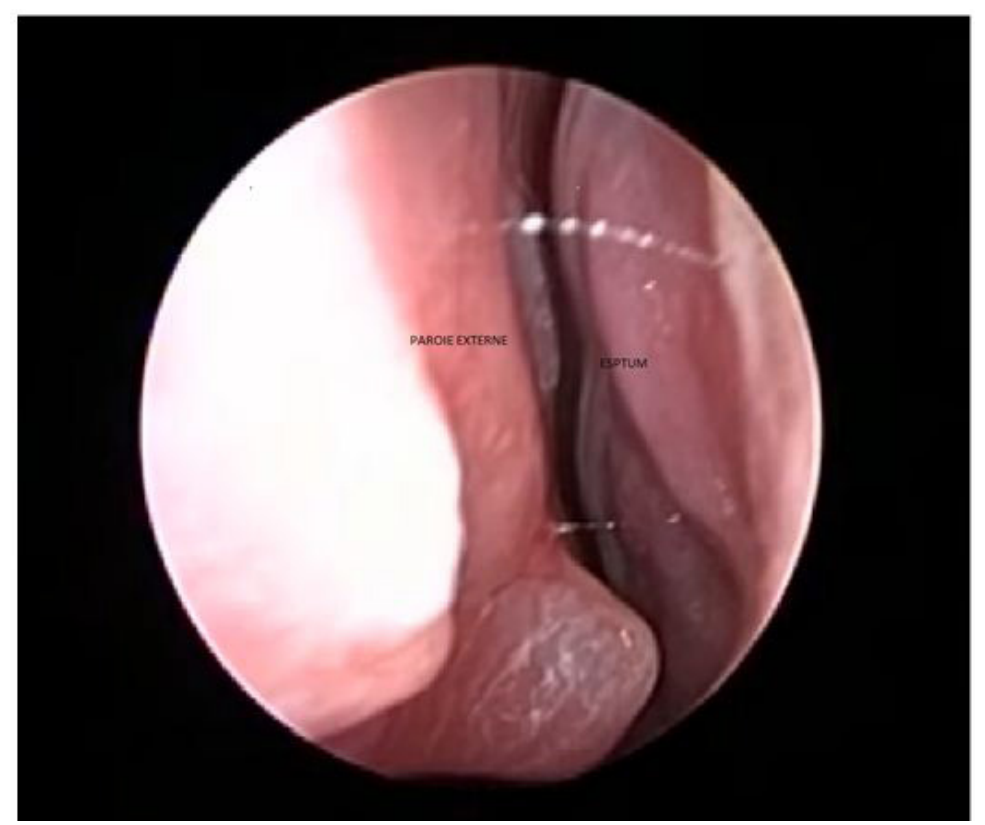


The facial CT scan (Figure 2) has showed a mass of calcium density with a lipid center adjacent to the floor of the right nasal fossa, in relation to an included tooth. Endoscopic surgery was performed under general anesthesia to remove the mass from its location.
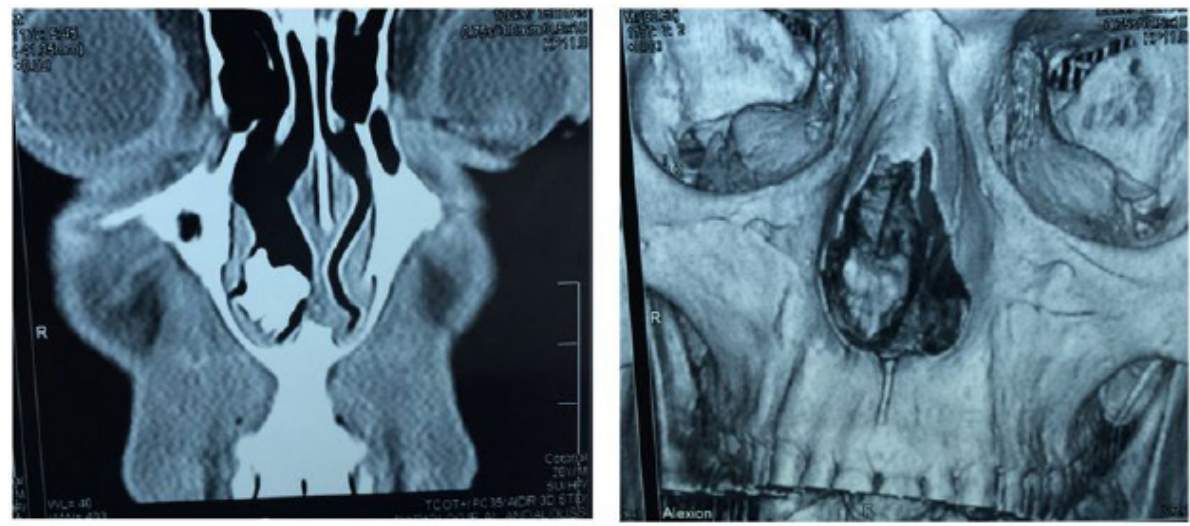

Figure 2: CT in coronal section and reconstruction showing a picture of calcium density in the level of the right nasal fossa

Histological study confirmed the dental nature of the mass.

Two months after surgery, right nasal cavity was normal, with no signs of recurrency (Figure 3).

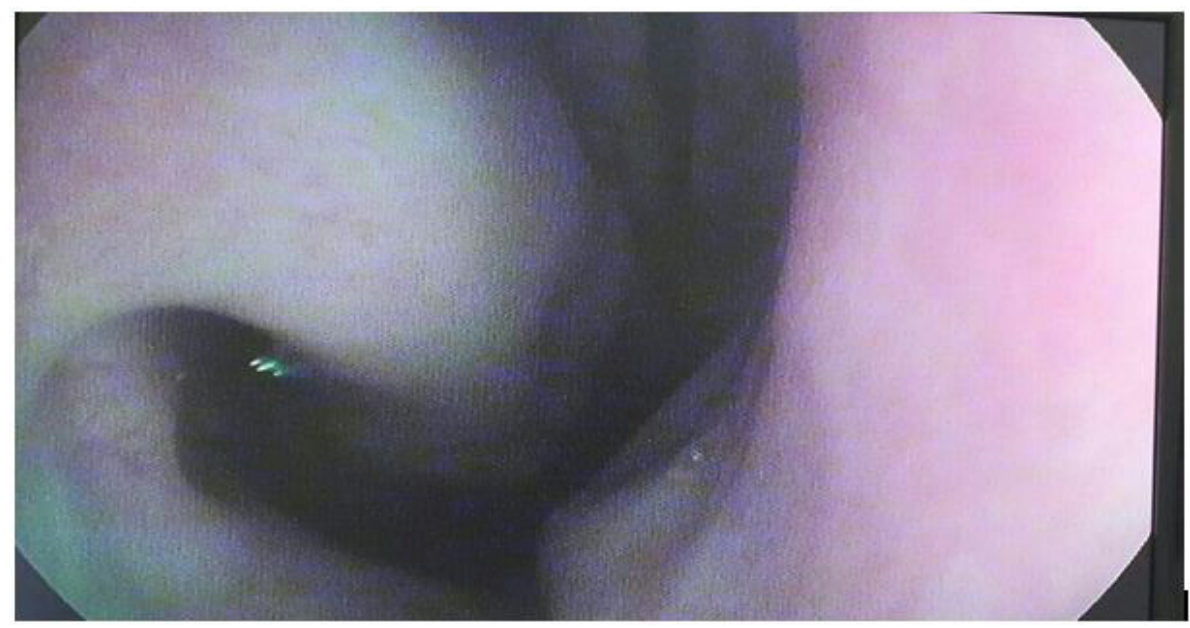

Figure 3: Endoscopic image showing a normal right nasal fossa after surgery

\section{Discussion}

An intranasal ectopic tooth remains a rare phenomenon. In the majority of cases reported in the literature, no etiological explanation was found [1]. However, a number of hypotheses were raised, such as the displacement of a dental bud following dental trauma, maxillary osteomyelitis, or the development of defect such as cleft palate [1].

In most cases, intranasal ectopic teeth are most commonly seen as a single unilateral tooth rather than several teeth or teeth in both nasal cavities $[2,3]$. The most frequent clinical signs are permanent unilateral nasal obstruction, facial pain and recurrent epistaxis [4,5]. Clinical examination reveals a whitish mass surrounded by granulation or a mass coated with reddish mucosa [2].

The imaging of an intranasal tooth finds an opaque mass of a density similar to the bone. The diagnosis is made based on radiological informations and proven by histology [6].

The treatment requires surgical removal, which usually relieves symptoms.

The surgery is a usually minor one [6]. The extraction of the nasal teeth can be carried out under endoscopic guidance, which offers clear visualization, good illumination and precise dissection to minimize the injuries of neighboring structures [7]. Histological study confirms the diagnosis.

\section{Conclusion}

Ectopic intranasal teeth are rare phenomenon, and can cause several symptoms. Early diagnosis and treatment are important to prevent morbidity from these nasal masses.

\section{Author's Contribution}

All the authors participated in the care of the patient, and in the realization of the article. All authors have read and approved the final version of the manuscript. 


\section{References}

1. Al Dhafeeri HO, Kavarodi A, Al Shaikh K, Bukhari A, Al Hussain O, et al. (2014) Recurrent epistaxis caused by an intranasal supernumerary tooth in a young adult. Am J Case Rep 15: 291-3.

2. Chao Yu, Deying Gu, Junnan An, Yuedi Tang (2015) Case Presentation of an Intranasal Ectopic Tooth in a Pediatric Patient. Am J Otolaryngol 36: $472-74$.

3. Verma RK, Bakshi J, Panda NK (2012) Ectopic intranasal tooth: an unusual cause of epistaxis in a child. Ear Nose Throat J 91: 242-4.

4. Gilbride MJ, Smith WP (2005) Eruption of teeth in the nose following trauma to the primary and permanent dentitions. Br Dent J 198: 199-200.

5. Chen A, Huang JK, Cheng SJ, Sheu CY (2002) Nasal teeth: report of three cases. AJNR Am J Neuroradiol 23: 671-3.

6. van Essen TA, van Rijswijk JB (2013) 'Intranasal toothache': case report. J Laryngol Otol 127: 321-2.

7. Kim DH, Kim JM, Chae SW, Hwang SJ, Lee SH, et al. (2003) Endoscopic removal of an intranasal ectopic tooth. Int J Pediatr Otorhinolaryngol 67: 79-81.

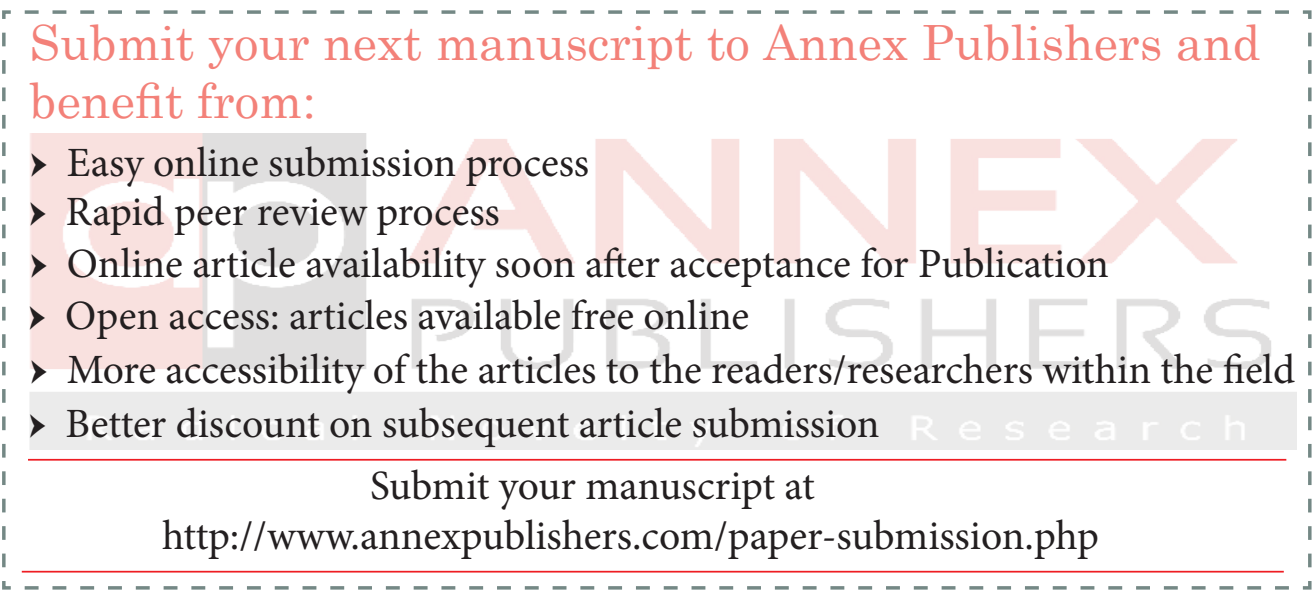

